\title{
Resveratrol-loaded nanoparticles inhibit enterovirus 71 replication through the oxidative stress-mediated ERS/autophagy pathway
}

\author{
NA DU, XIAO-HUA LI, WAN-GUO BAO, BIN WANG, GUANG XU and FENG WANG \\ Department of Infectious Diseases, The First Hospital of Jilin University, Changchun, Jilin 130021, P.R. China
}

Received October 19, 2018; Accepted May 23, 2019

DOI: $10.3892 / \mathrm{ijmm} .2019 .4211$

\begin{abstract}
A number of studies have demonstrated that resveratrol (RES) has a variety of biological functions, including cardiovascular protective effects, treatment of mutations, and anti-inflammatory, anti-tumor and antiviral effects. In the present study, RES-loaded nanoparticles (RES-NPs) were used to protect rhabdosarcoma (RD) cells from enterovirus 71 (EV71) infection, and the relevant mechanisms were also explored. An amphiphilic copolymer, monomethoxy poly (ethylene glycol)-b-poly (D,L-lactide), was used as vehicle material, and RES-NPs with necessitated drug-loading content and suitable sizes were prepared under optimized conditions. RES-NPs exhibited the ability to inhibit the increase of intracellular oxidative stress. The prospective mechanism for the function of RES-NPs suggested was that RES-NPs may inhibit the oxidative stress-mediated PERK/eIF2 $\alpha /$ ATF4 signaling pathway, downregulate the autophagy pathway and resist EV71-induced RD cells injury. Furthermore, RES-NPs treatment markedly inhibited the secretion of inflammatory factors, including interleukin (IL)-6, IL-8 and tumor necrosis factor- $\alpha$ elicited by EV71 infection. Concomitantly, inhibitors of oxidative stress, endoplasmic reticulum stress (ERS) or autophagy were demonstrated to negate the anti-inflammatory and antiviral effects of RES-NPs on EV71-infected RD cells. These results demonstrated that RES-NPs attenuated EV71-induced viral replication and inflammatory effects by inhibiting the oxidative stress-mediated ERS/autophagy signaling pathway. In view of their safety and efficiency, these RES-NPs have potential applications in protecting RD cells from EV71 injury.
\end{abstract}

Correspondence to: Professor Feng Wang, Department of Infectious Diseases, The First Hospital of Jilin University, 71 Xinmin Street, Changchun, Jilin 130021, P.R. China

E-mail: wangfeng3077@163.com

Key words: resveratrol, nanoparticles, enterovirus 71, oxidative stress, endoplasmic reticulum stress, autophagy

\section{Introduction}

Enteroviruses are a group of small single-strand, positive-sense RNA viruses in the Enterovirus genus of the Picornaviridae family (1-3). Infection with certain enteroviruses, including enterovirus 71 (EV71) and coxsackievirus B, lead to severe diseases including aseptic meningitis, brainstem encephalitis, myocarditis and pancreatitis $(4,5)$. Enterovirus infections are particularly common among children $<5$ years old, and it is one of the major causative pathogens of hand, foot and mouth disease (HFMD), which affects millions of children in the Asia-Pacific region (6,7). In 2015, there were up to 2 million patients with HFMD, with 129 mortalities reported in China. The clinical presentation of HFMD is characterized by buccal ulcerative lesions with pain, and skin rashes on hands and feet without pain (8). A small number of children may exhibit central nervous system and respiratory system damage, causing aseptic meningitis, encephalitis, acute flaccid paralysis, neurogenic pulmonary edema and myocarditis. Critically ill children progress rapidly, and are at risk of mortality (9). In recent years, there have been a number of treatments for EV infection, including vaccines, antivirals and interferon $(10,11)$. Unfortunately, the efficacy of these treatments is not satisfactory.

The primary active ingredient of Polygonum cuspidatum is polydatin and resveratrol (RES) (12). Polydatin has exhibited antitussive, hepatoprotective and anti-shock effects, and the ability to inhibit platelet aggregation, among other effects (13). RES is the most valuable and promising ingredient in P. cuspidatum, and it has antibacterial, anti-inflammatory, anti-allergic, anti-thrombotic, anti-oxidant, anti-cancer and anti-mutation effects (14-16). In addition, RES also has antiviral effects against certain viruses, including influenza virus, hepatitis $C$ virus, respiratory syncytial virus, Epstein-Barr virus, African swine fever virus, enterovirus and duck enteritis virus (17-18).

However, the solubility of RES is poor in aqueous solution, and it is easily degraded $(12,14)$. Therefore, RES has a low bioavailability, which results in a limited curative effect. Nanoparticle (NP) technology may improve the solubility and therapeutic effects of hydrophobic drugs (19-21). In the present study, in order to effectively inhibit the replication of EV71 virus, RES-loaded nanoparticles (RES-NPs) were used, and the protective mechanism of RES-NPs against rhabdosarcoma (RD) cells infected with EV71 was investigated. 


\section{Materials and methods}

Materials. RD cells were purchased from Nanjing Kangxi Biotechnology Co., Ltd. Dulbecco's modified Eagle's medium (DMEM), fetal bovine serum (FBS) and collagenase type II were purchased from Gibco; Thermo Fisher Scientific, Inc. The polyvinylidene fluoride membranes and enhanced chemiluminescence (ECL) western blot detection system were purchased from Pierce; Thermo Fisher Scientific, Inc. The malondialdehyde (MDA) assay and bicinchoninic acid (BCA) kits was purchased from Nanjing Jiancheng Bioengineering Institute. The superoxide dismutase (SOD) assay kit was purchased from Dojindo Molecular Technologies, Inc. The reactive oxygen species (ROS) assay kit was obtained from Applygen Technologies, Inc. Rabbit polyclonal antibodies against GAPDH, protein kinase R-like endoplasmic reticulum-resident kinase (PERK), phosphorylated-PERK (p-PERK), eukaryotic initiation factor $2 \alpha$ (eIF2 $\alpha$ ), phosphorylated-eIF2 $\alpha$ (p-eIF2 $\alpha$ ), activating transcription factor 4 (ATF4), glucose regulated protein 78 (GRP78), transcription factor CCAAT/enhancer binding protein (C/EBP)-homologous protein (CHOP) and light chain 3A/B (LC3-I/II) were purchased from Cell Signaling Technology, Inc. Major capsid protein VP1 (VP1), LC3B (LC3-II), horseradish peroxidase-linked rabbit anti-mouse IgG and $\mathrm{Cy} 3$-labeled goat anti-rabbit IgG were purchased from Abcam. MTT, RES, apocynin, 4-phenylbutyric acid (4-PBA) and 3-methyladenine (3-MA) reagents were purchased from Sigma-Aldrich; Merck KGaA.

Synthesis of RES-NPs. The synthesis of copolymer monomethoxy poly (ethylene glycol)-b-poly (D,L-lactide) (PEG-PDLLA) was performed as described previously (22). In detail, $4 \mathrm{ml}$ RES $(1 \mathrm{mg})$ and PEG-PDLLA $(9 \mathrm{mg})$ solution in tetrahydrofuran (THF) was slowly added into $10 \mathrm{ml}$ distilled water at room temperature and stirred; the mixture was dialyzed to remove THF. RES-NPs were obtained for subsequent use.

Characterization of RES-NPs. The morphology of RES-NPs was observed using transmission electron microscopy (TEM) as follows: Following dropping of the sample liquid on a carbon coated copper grid, it was dyed with $1 \%$ uranyl acetate. The size distribution of NPs was determined by dynamic light scattering (DLS) with a vertically polarized He-Ne laser (DAWN EOS; Wyatt Technology Corporation). Zeta potential measurement was performed using Zetasizer Nano-ZS (Malvern Instruments, Ltd.).

In vitro release. A total of $2 \mathrm{ml}$ PBS (pH 7.4, $1.0 \mathrm{wt} \%$ Tween-80) solution and RES-NPs were added to the dialysis bag (Molecular weight cutoff $=3.5 \mathrm{kDa}$ ), and the dialysis bag was placed in $8 \mathrm{ml}$ release medium and oscillated at $37^{\circ} \mathrm{C}$. At intervals of $2 \mathrm{~h}$, $1 \mathrm{ml}$ buffer solution was removed from the dialysis bag for UV visualization, and $1 \mathrm{ml}$ fresh buffer solution was added to the dialysis bag. The calibration curve of RES was obtained based on the absorbance of RES at $306 \mathrm{~nm}$. Finally, the cumulative release weight and relative percentage of RES were obtained.

Cytotoxicity test. Cell suspensions were seeded in 96-well plates $\left(1 \times 10^{5}\right.$ cells per well, $100 \mu 1$ per well). The culture solution containing RES $(200 \mu \mathrm{g} / \mathrm{ml})$ or RES-NPs (RES concentration, $200 \mu \mathrm{g} / \mathrm{ml}$ ) was added to each well, and the culture plate was placed in an incubator $\left(37^{\circ} \mathrm{C}\right.$ and $\left.5 \% \mathrm{CO}_{2}\right)$ for $48 \mathrm{~h}$. Following incubation, the supernatant was discarded and $20 \mu 1$ MTT solution ( $5 \mathrm{mg} / \mathrm{ml}$ in PBS) was added to each well. The culture plate was placed in the incubator $\left(37^{\circ} \mathrm{C}\right.$ and $5 \% \mathrm{CO}_{2}$ ) and incubated for $4 \mathrm{~h}$ prior to removal of the supernatant. Dimethyl sulfoxide $(150 \mu \mathrm{l})$ was added to each of the 96-well plates, and the absorbance at $570 \mathrm{~nm}$ was measured by a microplate reader (Bio-Rad Laboratories, Inc.). Finally, the $50 \%$ cytotoxic concentration $\left(\mathrm{CC}_{50}\right)$ was calculated.

Virus isolation and propagation. A total of $4 \mathrm{ml}$ EV71 medium $(\mathrm{MOI}=2)$ was prepared as a virus inoculum. Following culture for $24 \mathrm{~h}, \mathrm{RD}$ cells were washed once with PBS, diluted to a density of $1 \times 10^{6}$ cells, and incubated with the prepared EV71 medium for $1.5 \mathrm{~h}$ at $37^{\circ} \mathrm{C}$. To remove unbound EV71, the cells were washed with fresh medium. Cell supernatants were collected at $0,1,3,6,12,16,18,20$ and $24 \mathrm{~h}$ after infection, virus titers were determined by cytopathic effect (CPE), and the median tissue culture infectious dose (TCID50) per ml was calculated. The results were observed and recorded daily for 5-7 days; CPE was observed under a light microscope (magnification, $\mathrm{x} 100$ ) and categorized according to the following criteria: i) -: no cytopathic changes; ii) \pm : $1-25 \%$ of the cells had pathological changes; iii) $++: 26-50 \%$ of the cells had pathological changes; iv) +++: $51-75 \%$ of the cells had pathological changes; and v) +++: $76-100 \%$ of the cells had pathological changes. The number of positive holes in each row was counted and the virus TCID50 was calculated using the Reed-Muench method (23) or Karber method (24). If there was no CPE in the negative control group and the cells grew well, the lowest dilution was $100 \%$ positive and the highest dilution was $100 \%$ negative, the test would be effective.

Antiviral activity assay. Following culture of the RD cells in 96-well plates for $24 \mathrm{~h}, 30 \mu \mathrm{l} \mathrm{EV71} \mathrm{(MOI=2)} \mathrm{medium} \mathrm{and}$ diluted RES-NPs solution were added and incubated for $1.5 \mathrm{~h}$ at $37^{\circ} \mathrm{C}$. In order to remove the virus that was not absorbed, the medium was aspirated. The cells were washed with PBS and RES $(200 \mu \mathrm{g} / \mathrm{ml})$ or RES-NPs (RES concentration, $200 \mu \mathrm{g} / \mathrm{ml}$ of each group (doses were $\leq$ toxic dose) were added. The CPE of each group was observed using a light microscope (magnification, x100) and subjected to MTT measurement as aforementioned, and finally the half-maximal inhibitory dose value $\left(\mathrm{IC}_{50}\right)$ was calculated.

Time course analysis of RES-NPs on EV71 replication. $\mathrm{RD}$ cells $\left(3 \times 10^{5}\right.$ cells/well) were inoculated in a 96-well plate for $24 \mathrm{~h}$, and the control, RES $(200 \mu \mathrm{g} / \mathrm{ml})$ or RES-NPs (RES concentration $=200 \mu \mathrm{g} / \mathrm{ml}$ ) groups were infected with EV71 $(\mathrm{MOI}=2)$ for $1.5 \mathrm{~h}$. Cell supernatants were then collected at different assay times $(0,1,3,6,12,16,18,20$ and $24 \mathrm{~h})$ post-infection, and EV71 titers were determined by calculating the TCID50 values.

Measurement of ROS levels. Dihydroethidium [DHE; Weigras Biotechnology (Beijing) Co., Ltd], a ROS-level indicative fluorescence probe $\left(\lambda_{\mathrm{ex}}=535 \mathrm{~nm}, \lambda_{\mathrm{em}}=610 \mathrm{~nm}\right)$, was used to detect intracellular superoxide anions. Briefly, RD cells were seeded 
in 6-well plates $\left(2 \times 10^{4}\right.$ cells/well) and cultured with complete medium for $24 \mathrm{~h}$. Cells were then divided into different groups and exposed to culture medium (control) or EV71 or EV71 + RES-NPs (RES concentration $=200 \mu \mathrm{g} / \mathrm{ml}$ ), respectively, for $24 \mathrm{~h}$ at $37^{\circ} \mathrm{C}$. Subsequently, cells were washed with cold PBS and additionally incubated with fresh medium containing $10 \mu \mathrm{M} \mathrm{DHE}$ at $37^{\circ} \mathrm{C}$ in the dark for $20 \mathrm{~min}$ to stain the nuclei. The harvested cells were resuspended in PBS at a density of $2 \times 10^{7}$ cells $/ \mathrm{ml}$, transferred to a light-shielded 96-well plate (100 $\mu$ l cell suspension per well), followed by determination of DHE intensity using a fluorescence microplate reader (Bio-Rad Laboratories, Inc.). Fluorescence images of the cells were captured using an electronic camera (Olympus Corporation).

Determination of major biochemical parameters. MDA and SOD levels were measured using MDA and SOD activity kits, respectively. Briefly, RD cells that were cultured with complete medium for $24 \mathrm{~h}$ were divided into different groups, and these groups were treated with culture medium (control) or EV71 or EV71 + RES-NPs (RES concentration=200 $\mu \mathrm{g} / \mathrm{ml}$ ) for $24 \mathrm{~h}$ at $37^{\circ} \mathrm{C}$. The harvested cells were lysed and the supernatant was collected by centrifugation at $12,000 \mathrm{x}$ g for $10 \mathrm{~min}$ at $4^{\circ} \mathrm{C}$. Protein content in the supernatant was detected using a BCA kit. In addition, $100 \mu \mathrm{l}$ supernatant was placed into a centrifuge tube, and the MDA testing solution (200 $\mu \mathrm{l})$ was added. Following mixing, the mixture was boiled for $15 \mathrm{~min}$ and cooled to room temperature, followed by centrifugation at $1,000 \mathrm{x} \mathrm{g}$ for $10 \mathrm{~min}$ at $4^{\circ} \mathrm{C}$. A total of $200 \mu 1$ prepared supernatant was added to 96 -well plate, and the absorbance was measured at $532 \mathrm{~nm}$ using a microplate reader (Bio-Rad Laboratories, Inc.).

SOD was detected based on its ability to inhibit superoxide-mediated reduction. A SOD assay kit (cat. no. S311; Dojindo Molecular Technologies, Inc.) was used to detect its activity. The harvested cells were homogenized, and the obtained homogenate was centrifuged at $12,000 \mathrm{x} \mathrm{g}$ for $10 \mathrm{~min}$ at $4^{\circ} \mathrm{C}$. The protein content in supernatant was determined using the BCA kit. A mixture of $20 \mu \mathrm{l}$ supernatant and $160 \mu \mathrm{l}$ nitro-blue tetrazolium chloride/enzymatic working solution was added to a centrifuge tube, and mixed at $4^{\circ} \mathrm{C}$ for $5 \mathrm{~min}$. Then, $20 \mu \mathrm{l}$ reaction-initiating working solution was added and incubated at $37^{\circ} \mathrm{C}$ for $30 \mathrm{~min}$. The resultant mixture was detected for its absorbance at $560 \mathrm{~nm}$ using the aforementioned microplate reader.

Western blot analysis. The cells in each group were cultured in a $37^{\circ} \mathrm{C}, 5 \% \mathrm{CO}_{2}$ incubator for $24 \mathrm{~h}$ and the supernatant was discarded. The cells were lysed with 1X RIPA lysis buffer (Cell Signaling Technology, Inc.). The cells were then collected in a centrifuge tube and centrifuged at $12,000 \times \mathrm{g}$ for $15 \mathrm{~min}$ at $4^{\circ} \mathrm{C}$. The lysates were clarified, and the supernatants fractions were isolated. Protein concentrations in cells were determined using a bicinchoninic acid protein assay. In total, 30-50 $\mu \mathrm{g}$ of protein was loaded and separated by SDS-PAGE on $8-12 \%$ gels and then transferred to a PVDF membrane. After blocking the membrane with $5 \%$ non-fat milk for $1 \mathrm{~h}$ at room temperature, the following primary antibodies were used for western blotting: VP1 (cat. no. ab53977; 1:10,000), PERK (cat. no. 3192; 1:1,000), p-PERK (cat. no. 3179; 1:1,000), eIF2 $\alpha$ (cat. no. 9722; 1:1,000), p-eIF2 $\alpha$ (cat. no. 3398; 1:1,000), ATF4 (cat. no. 11815; 1:1,000),
GRP78 (cat. no. 3183; 1:1000), CHOP (cat. no. 2895; 1:1,000), LC3-I/II (cat. no. 4108; 1:1,000) and GAPDH (cat. no. 5174; 1:1,000). Primary antibodies were incubated with membranes overnight at $4^{\circ} \mathrm{C}$. The membrane was incubated with horseradish peroxidase-linked rabbit anti-mouse IgG (cat. no. ab6728; $1: 2,000$ ) for $2 \mathrm{~h}$ at room temperature. Finally, the blots were visualized using a chemiluminescence system (Pierce; Thermo Fisher Scientific, Inc.). GeneTools software 4.1 (Syngene) was used to quantify the immunoblots.

Immunofluorescence analysis. The cells in each group were cultured in a $37^{\circ} \mathrm{C}, 5 \% \mathrm{CO}_{2}$ incubator for $24 \mathrm{~h}$, the cells were fixed with $4 \%$ paraformaldehyde for $20 \mathrm{~min}$ at room temperature and blocked with $1 \%$ bovine serum albumin (cat. no. B2064; Sigma-Aldrich; Merck KGaA) for $30 \mathrm{~min}$ at room temperature. After washing the cells with PBS, the cells were incubated with primary antibodies against LC3-II (cat. no. ab48394; $1: 400$ ) for $24 \mathrm{~h}$ at $4^{\circ} \mathrm{C}$. After washing with PBS, the cells were incubated with Cy3-labeled goat anti-rabbit IgG (cat. no. ab150077; 1:200) for $60 \mathrm{~min}$ at room temperature. DAPI $(5 \mathrm{mg} / \mathrm{ml})$ was used to stain all cell nuclei at room temperature for $10 \mathrm{~min}$. A fluorescence microscope (magnification, $\mathrm{x} 400$; Olympus Corporation) was used to observe the morphology of the cells and the intensity of the fluorescent signals.

Detection of inflammatory cytokines. RD cells infected with EV71 (MOI=2) were centrifuged at $1,500 \mathrm{x} \mathrm{g}$ for $10 \mathrm{~min}$ at $4^{\circ} \mathrm{C}$, and the supernatant was collected at $0,3,6,12$ and $24 \mathrm{~h}$ after infection. The concentration of interleukin (IL)-6, IL-8 and tumor necrosis factor- $\alpha(\mathrm{TNF}-\alpha)$ in the supernatant was measured by Milliplex magnetic beads (EMD Millipore) and the FLEXMAP 3D platform (Luminex Corporation). The resulting data was analyzed by MILLIPLEX Analyst v5.1 (VigeneTech, Inc.).

Statistical analysis. All experiments were performed a minimum of 3 times, and the data were analyzed using GraphPad Prism v5 software (GraphPad Software, Inc.). All data are presented as the mean \pm standard deviation, and were analyzed using one-way analysis of variance followed by Tukey's post-hoc test. $\mathrm{P}<0.05$ was considered to indicate a statistically significant difference.

\section{Results}

Preparation of RES-NPs. The THF solution containing RES and PEG-PDLLA was dropped into water, and ideal RES-NPs were obtained. Fig. 1A illustrates the Gaussian distribution of RES-NP size. The particle size and zeta potential of the obtained RES-NPs were $144.7 \mathrm{~nm}$ (polydispersity index=0.31) and $0.47 \pm 0.012 \mathrm{mV}$, respectively. TEM data indicated that RES-NPs were spherical nanoparticles with diameters of $\sim 145$ nm (Fig. 1B). All these data indicate that RES-NPs had small sizes and nearly neutral surface charge, suggesting that they have potential for practical applications.

Release profile of RES-NPs. In order to calculate the cumulative release rate of RES, the released RES were collected at different time points. As demonstrated in Fig. 2, the release of 

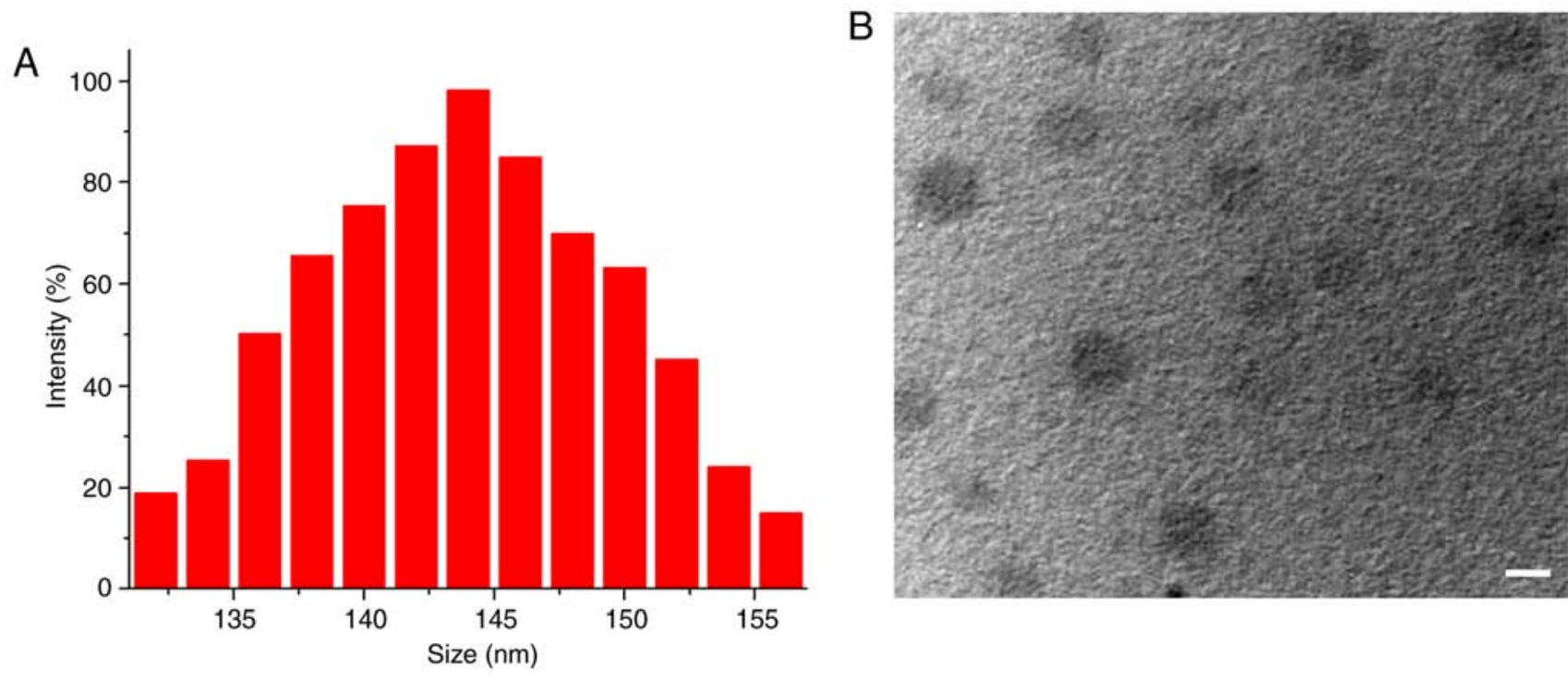

Figure 1. Size distribution and TEM image of RES-NPs. (A) Size distribution of RES-NPs determined by dynamic light scattering. (B) Representative TEM image of RES-NPs. Scale bar, $100 \mathrm{~nm}$. TEM, transmission electron microscope; RES-NPs, resveratrol-loaded nanoparticles.

RES was rapid during the first $4 \mathrm{~h}$, with a cumulative release rate of up to $40 \%$, but after $4 \mathrm{~h}$, RES release became slow, due to the strong hydrophobicity of RES (25).

Effect of RES-NPs on viability of RD cells. To understand the toxicity of RES-NPs and RES on RD cells, different concentrations of RES-NPs and RES were added to RD cells and incubated for $48 \mathrm{~h}$ to detect cell viability. As indicated in Fig. 3, RES-NPs and RES were not significantly toxic to RD cells at 200 and $40 \mu \mathrm{g} / \mathrm{ml}$, respectively. However, when the concentration of RES-NPs and RES was $>200$ and $40 \mu \mathrm{g} / \mathrm{ml}$, respectively, the toxicity increased markedly. The $\mathrm{CC}_{50}$ of RES-NPs and RES were 618.54 and $82.77 \mu \mathrm{g} / \mathrm{ml}$, respectively.

Antiviral effect of RES-NPS. To understand the association between RES-NPs treatment time and antiviral efficacy, 2 assays were performed. The first assay involved the addition of RES-NPs and EV71 to RD cells concomitantly, and the virus titer was detected after $48 \mathrm{~h}$. The second assay involved the addition of RES-NPs following EV71 infection of RD cells for $1.5 \mathrm{~h}$, and the virus titer was detected after $48 \mathrm{~h}$ of RES-NPs treatment. As indicated in Fig. 4A, RES-NPs significantly inhibited the replication of EV71 in a dose-dependent manner in both groups, and there was no significant difference between the two groups.

To additionally understand the time-dependent antiviral effect of RES or RES-NPs, EV71 was added to RD cells and incubated for $1.5 \mathrm{~h}$, then added RES $(200 \mu \mathrm{g} / \mathrm{ml})$ or RES-NPs (RES concentration $=200 \mu \mathrm{g} / \mathrm{ml}$ ) and incubated for different times. As demonstrated in Fig. 4B, RES or RES-NPs significantly inhibited EV71 replication during incubation for 6-24 h. On the basis of this result, the effect of RES or RES-NPs on VP1 synthesis was additionally analyzed. The results indicated that VP1 was significantly decreased in the presence of RES $(200 \mu \mathrm{g} / \mathrm{ml})$ or RES-NPs (RES concentration $=200 \mu \mathrm{g} / \mathrm{ml})$ at 6 , 12 and $24 \mathrm{~h}$, suggesting that RES or RES-NPs may effectively inhibit viral replication in EV71-infected RD cells (Fig. 4C). These results suggested that there was no significant difference

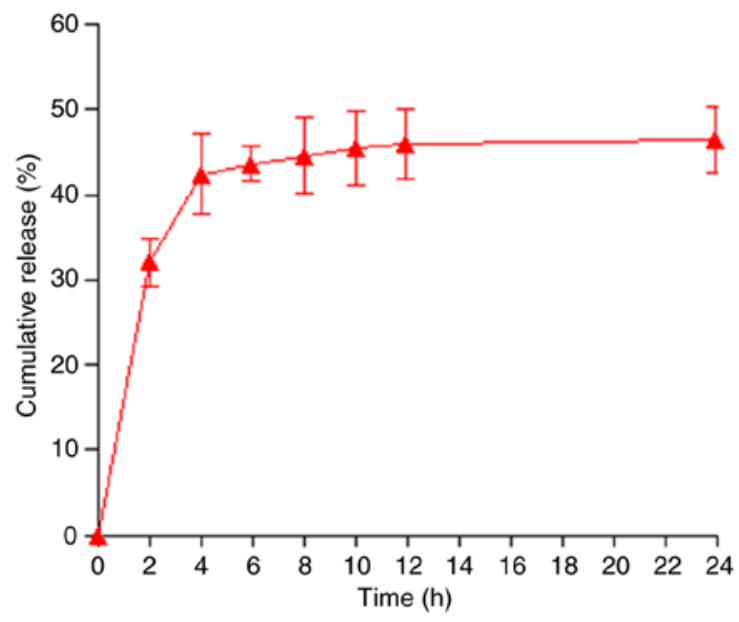

Figure 2. Cumulative release profiles of resveratrol from resveratrol-loaded nanoparticles in $\mathrm{pH} 7.4 \mathrm{PBS}$ for $24 \mathrm{~h}$.

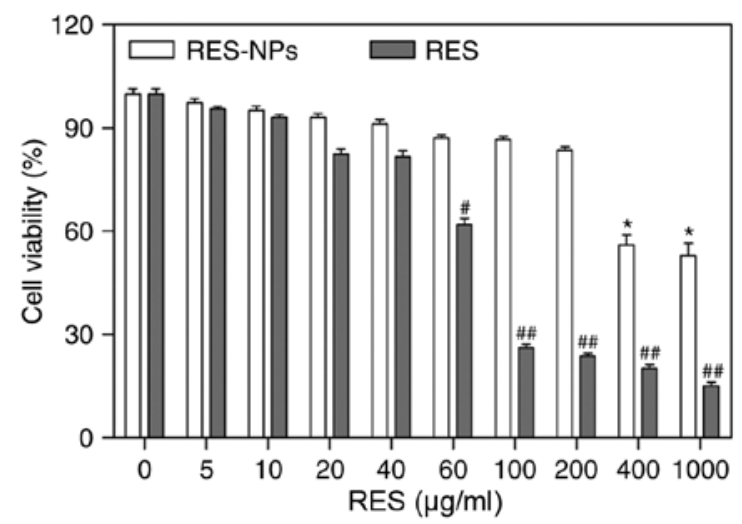

Figure 3. Cytotoxic effects of RES-NPs or RES on rhabdosarcoma cells. The cytotoxicity of RES-NPs or RES on rhabdosarcoma cells was determined by quantifying the cell viability by an MTT assay. The absorbance was measured using a microplate reader at $570 \mathrm{~nm}$. Data from three repeat experiments are presented as the mean \pm standard deviation. ${ }^{*} \mathrm{P}<0.05$ vs. 0 RES-NPs $\mu \mathrm{g} / \mathrm{ml}$ group (white bar); ${ }^{\#} \mathrm{P}<0.05$ and ${ }^{\# \#} \mathrm{P}<0.01$ vs. $0 \mu \mathrm{g} / \mathrm{ml}$ RES group (gray bar). RES, resveratrol; RES-NPs, resveratrol-loaded nanoparticles. 
C
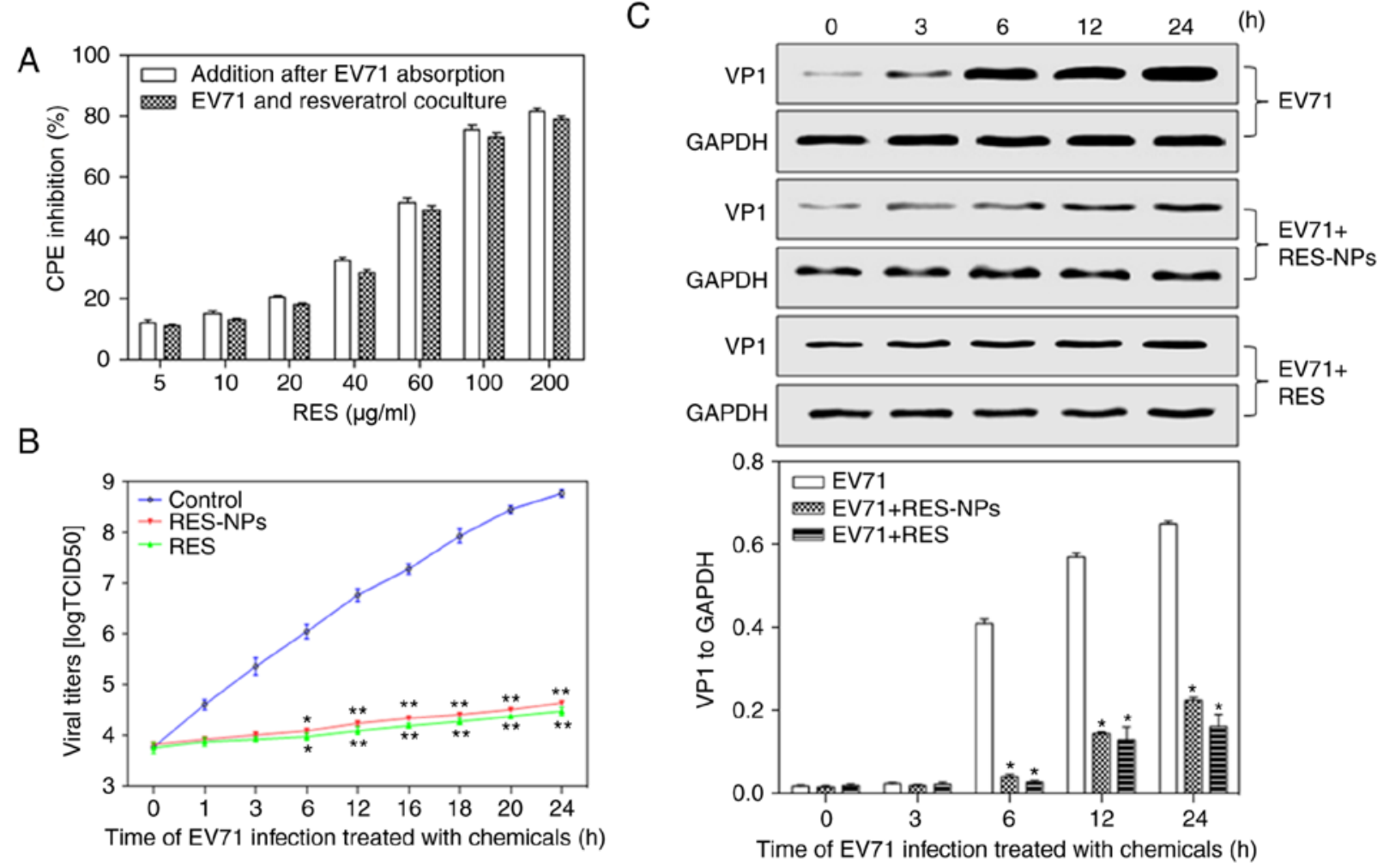

Figure 4. Antiviral effects of RES-NPs on EV71 replication in RD cells. (A) Various doses of RES-NPs were added with EV71 concomitantly, or following EV71 absorption for $1.5 \mathrm{~h}$. (B) RES $(200 \mu \mathrm{g} / \mathrm{ml})$ or RES-NPs (RES concentration= $200 \mu \mathrm{g} / \mathrm{ml})$ were added following EV71 absorption for $1.5 \mathrm{~h}$. The culture supernatants were collected at $0,1,3,6,12,16,18,20$ and $24 \mathrm{~h}$. Data from three repeat experiments are presented as the mean \pm standard deviation. ${ }^{*} \mathrm{P}<0.05$ and ${ }^{* *} \mathrm{P}<0.01$ vs. control group. (C) Inhibition of RES or RES-NPs on the expression of VP1 protein. At $0,3,6,12$ and $24 \mathrm{~h}$, RD cell lysates were subjected to $10 \%$ SDS-PAGE and transferred to polyvinylidene fluoride membranes to determine the expression level of VP1. Data from three repeat experiments are presented as the mean \pm standard deviation. VP1 levels were normalized with GAPDH. ${ }^{*}<<0.05$ vs. EV71. RES, resveratrol; RES-NPs, resveratrol-loaded nanoparticles; EV71, enterovirus 71; RD, rhabdosarcoma; VP1, major capsid protein VP1; CPE, cytopathic effect.

in the antiviral efficacy of RES-NPs $(200 \mu \mathrm{g} / \mathrm{ml})$ and RES $(200 \mu \mathrm{g} / \mathrm{ml})$ within $24 \mathrm{~h}$ of stimulation. The reason was that, although the cumulative release of RES released by RES-NPs was only $\sim 40 \%$ at $24 \mathrm{~h}$ of stimulation, the sustained release of NPs maintained a high level of local RES cellular concentration and prolonged the effective drug action time. Therefore, the antiviral effect was able to reach the levels observed for the small molecule RES.

Effect of RES-NPs on EV71-induced ROS level, MDA content and SOD activity in RD cells. EV71-induced ROS levels were first detected by using DHE as a fluorescent probe, and the results are presented in Fig. 5. The images denote that the RD cells treated with EV71 alone exhibited brighter red fluorescence signals compared with the control group, suggesting that EV71 infection may lead to an increase in intracellular ROS levels. Conversely, the red fluorescence corresponding to the cells treated with the combination of EV71 and RES-NPs exhibited largely decreased brightness when compared with those cells treated by EV71 only, demonstrating that RES-NPs may significantly prevent intracellular ROS production. DHE fluorescence intensity was quantified, and the data suggested that RES-NPs may completely inhibit the EV71-induced increase in ROS levels (Fig. 5B).

The data presented in Fig. 5C and D demonstrate that the EV71 infection resulted in a marked increase in the level of MDA, while leading to a significant decrease in SOD activity; these changes are markedly associated with the rise of intracellular oxidative stress levels. In contrast to these observations, RES-NPs (RES concentration $=200 \mu \mathrm{g} / \mathrm{ml}$ ) markedly inhibited the increase of MDA levels and regulated the SOD activity, ensuring that these indexes remained at normal levels.

Effect of RES-NPs on EV71-induced endoplasmic reticulum stress (ERS) upregulation in RD cells. The endoplasmic reticulum (ER) is an organelle responsible for the synthesis and folding of secreted proteins and transmembrane proteins (26). When the ER is in a resting state, GRP78 binds to baroreceptors and maintains the ER homeostasis (26). Viral infection may lead to the accumulation of misfolded proteins in the ER, which triggers ERS (27). ERS may contribute to autophagy via activation of GRP78, PERK, eIF2 $\alpha$, ATF4 and CHOP. In the present study, EV71 infection upregulated the expression of p-PERK, p-eIF2 $\alpha$ and ATF4 in RD cells at 6,12 and $24 \mathrm{~h}$ (Fig. 6A), but a significant decrease in their expression in the presence of RES-NPs (RES concentration $=200 \mu \mathrm{g} / \mathrm{ml}$ ) was observed (Fig. 6B). Concomitantly, RES-NPs failed to inhibit the expression of p-PERK, p-eIF2 $\alpha$ and ATF4 when pretreated with apocynin, an oxidative stress inhibitor (Fig. 6C). In addition, EV71 infection upregulated the expression of GRP78 and CHOP in RD cells at 6, 12 and $24 \mathrm{~h}$ (Fig. 6D), but a significant decrease in their expression in the presence of RES-NPs (RES concentration $=200 \mu \mathrm{g} / \mathrm{ml}$ ) was observed 

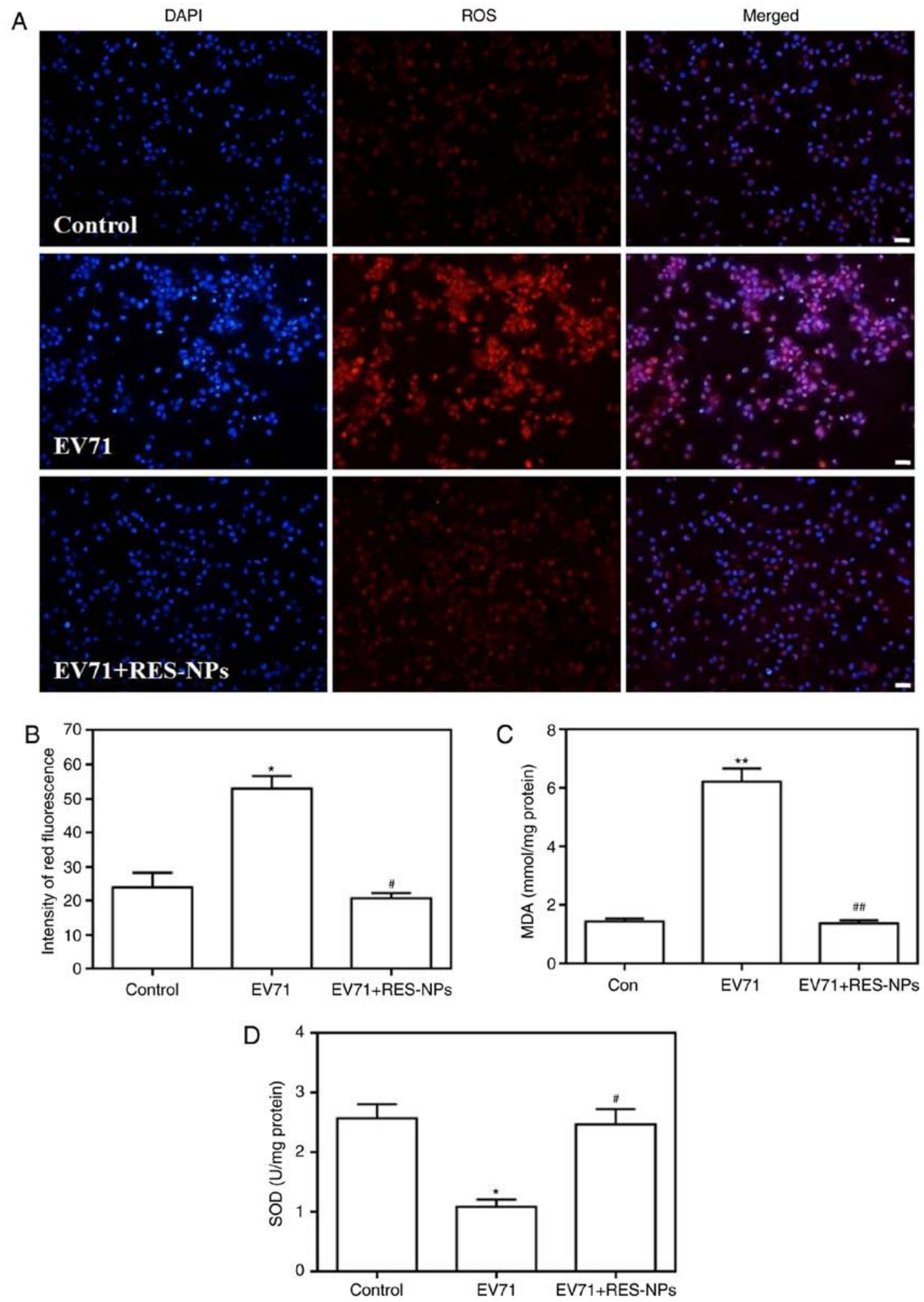

Figure 5. Fluorescence images and major biochemical parameters of RD cells treated with EV71 alone and the combination of EV71 and RES-NPs for $24 \mathrm{~h}$. (A) Representative images of ROS-positive cells (RES concentration, $200 \mu \mathrm{g} / \mathrm{ml}$; scale bar, $50 \mu \mathrm{m}$ ). (B) Fluorescence intensity of dihydroethidium signals. (C) MDA levels in RD cells. (D) SOD activity in RD cells. Data of three repeat experiments are presented as the mean \pm standard deviation. ${ }^{*} \mathrm{P}<0.05$ and ${ }^{* *} \mathrm{P}<0.01$ vs. control; ${ }^{\#} \mathrm{P}<0.05$ and ${ }^{\# \#} \mathrm{P}<0.01$ vs. EV71. RD, rhabdosarcoma; EV71, enterovirus 71; RES-NPs, resveratrol-loaded nanoparticles; ROS, reactive oxygen species; RES, resveratrol; MDA, malondialdehyde; SOD, super oxide dismutase.

(Fig. 6E). Furthermore, RES-NPs failed to inhibit the expression of GRP78 and CHOP when pretreated with apocynin (Fig. 6F). These data indicated that the RES-NPs inhibited the EV71-induced activation of the oxidative stress-mediated ERS signal pathway.
Effect of RES-NPs on EV71-induced autophagy upregulation in $R D$ cells. Autophagy is a type of programmed cell death through which the body degrades old proteins and senescent organelles, to achieve their own metabolic needs and organelle renewal (28-30). Under normal conditions, the level of 

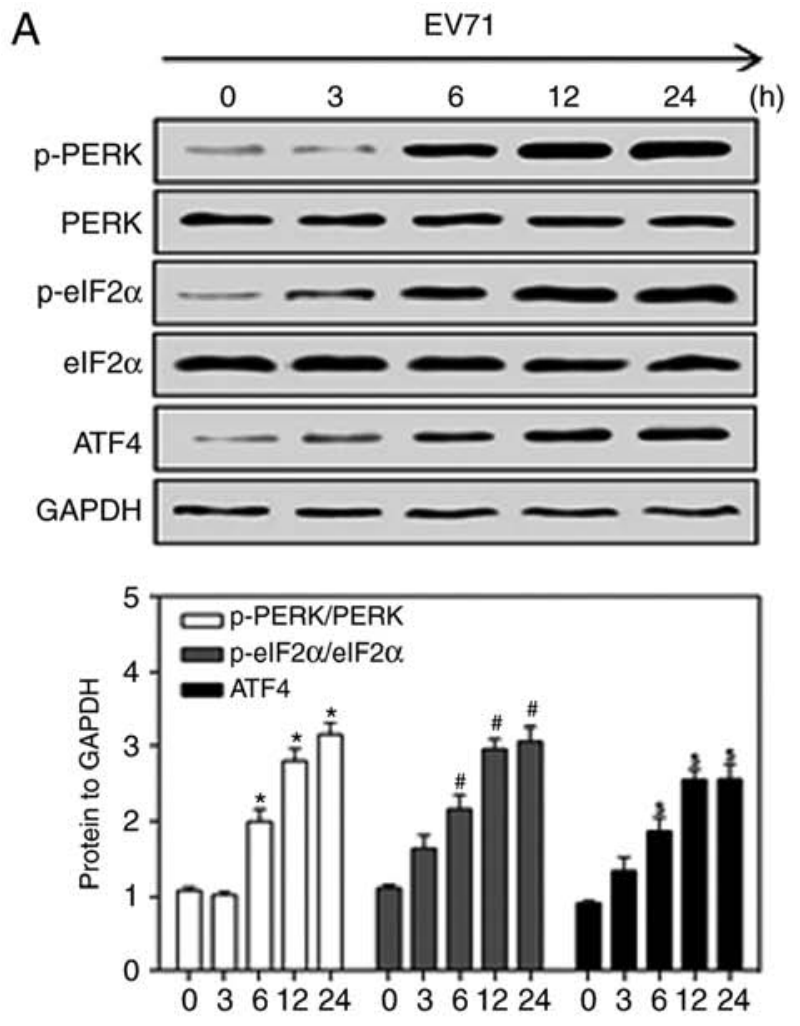

Time of EV71 infection treated with chemicals $(h)$
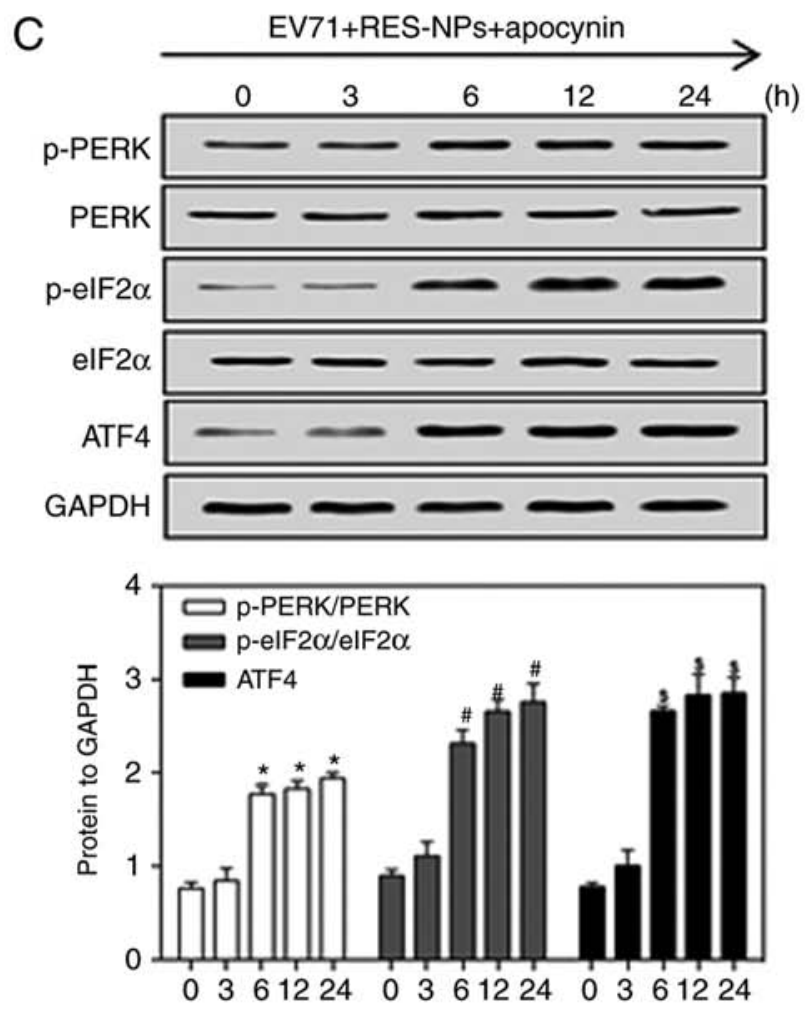

Time of EV71 infection treated with chemicals $(\mathrm{h})$
B
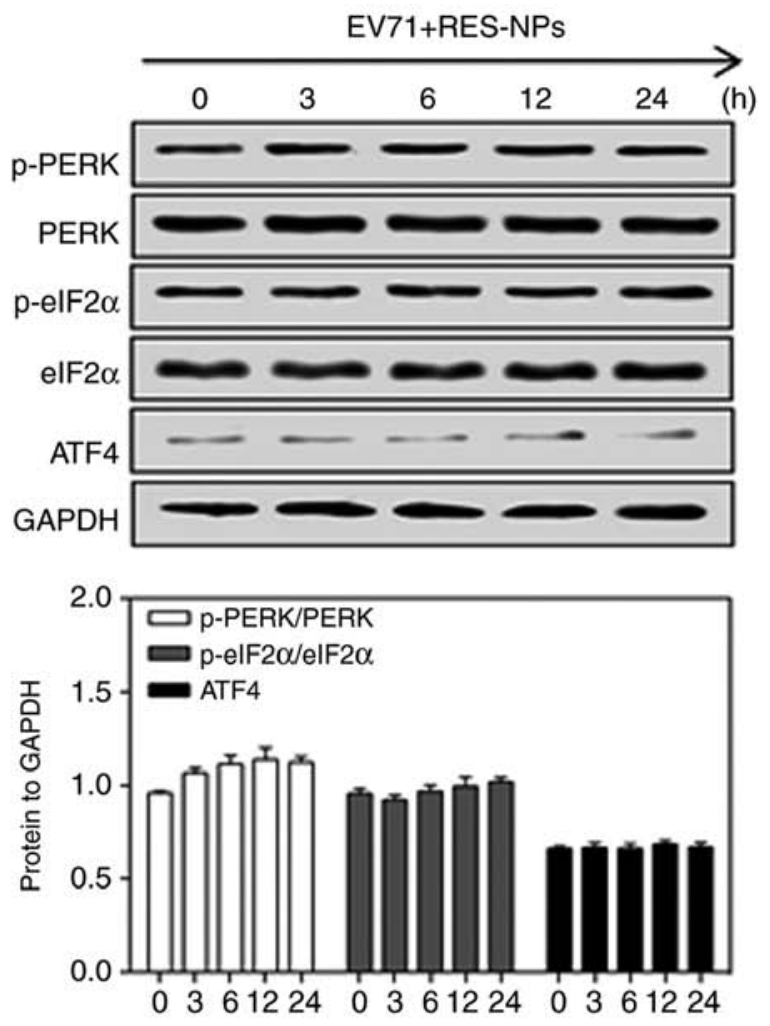

Time of EV71 infection treated with chemicals (h)
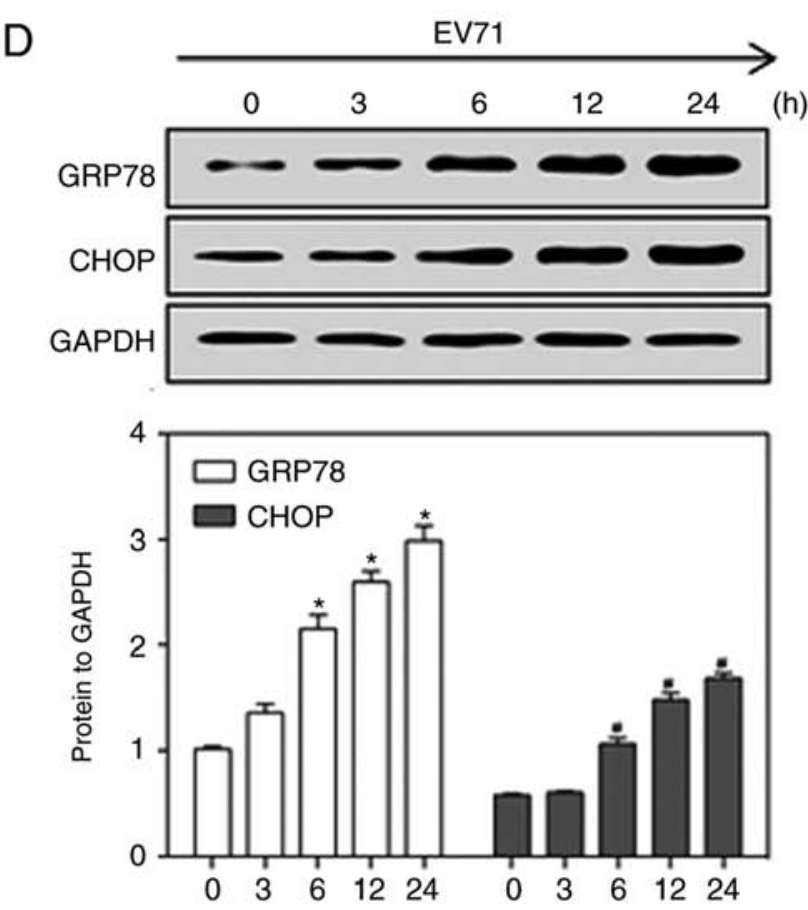

Time of EV71 infection treated with chemicals (h)

Figure 6. RES-NPs alters the expression levels of the endoplasmic reticulum stress-associated proteins p-PERK, PERK, p-eIF2 $\alpha$, eIF2 $\alpha$, ATF4, GRP78 and CHOP in EV71-infected RD cells. The levels of p-PERK, PERK, p-eIF2 $\alpha$, eIF2 $\alpha$ and ATF4 were measured in RD cells pretreated with (A) culture medium, (B) RES-NPs (RES concentration, $200 \mu \mathrm{g} / \mathrm{ml}$ ) alone or (C) RES-NPs (RES concentration, $200 \mu \mathrm{g} / \mathrm{ml}$ ) + apocynin $(300 \mu \mathrm{M})$ for $0,3,6,12$ and $24 \mathrm{~h}$ using a western blot assay following protein extraction. p-PERK and p-eIF2 $\alpha$ levels were normalized to PERK and eIF2 $\alpha$, and then normalized to GAPDH. ATF4 levels were normalized to GAPDH. The levels of GRP78 and CHOP were measured in RD cells pretreated with (D) culture medium for $0,3,6,12$ and $24 \mathrm{~h}$ using a western blotting assay following protein extraction. Data from three repeat experiments are presented as the mean \pm standard deviation. ${ }^{*} \mathrm{P}<0.05 \mathrm{vs} .0 \mathrm{~h}$ p-PERK/PERK group; ${ }^{\#} \mathrm{P}<0.05$ vs. $0 \mathrm{~h}$ p-eIF $2 \alpha / \mathrm{eIF} 2 \alpha$ group; ${ }^{\mathrm{S}} \mathrm{P}<0.05$ vs. $0 \mathrm{~h}$ ATF4 group. 

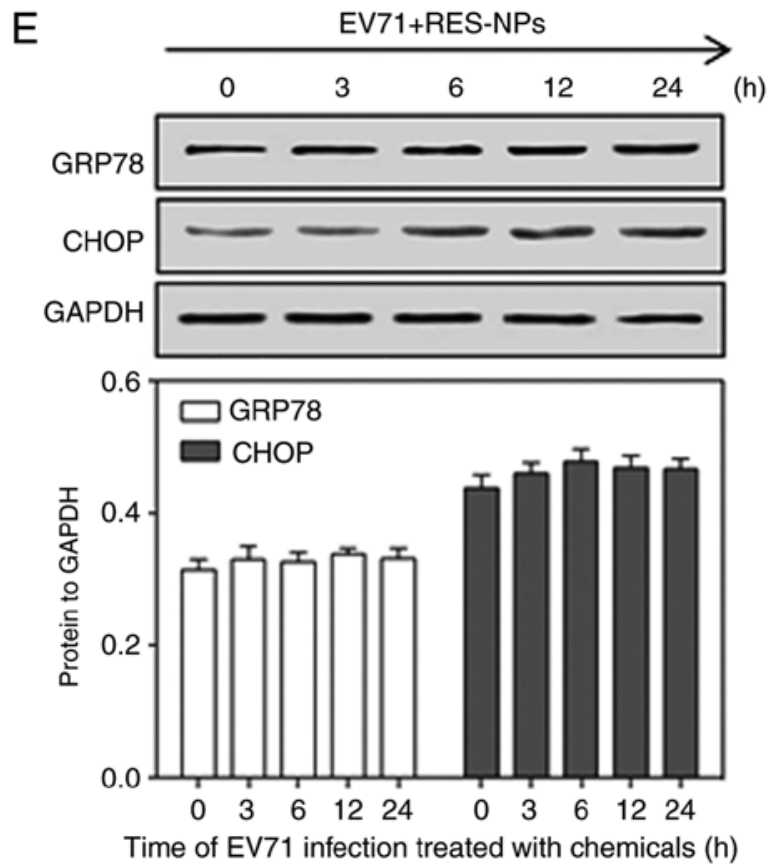
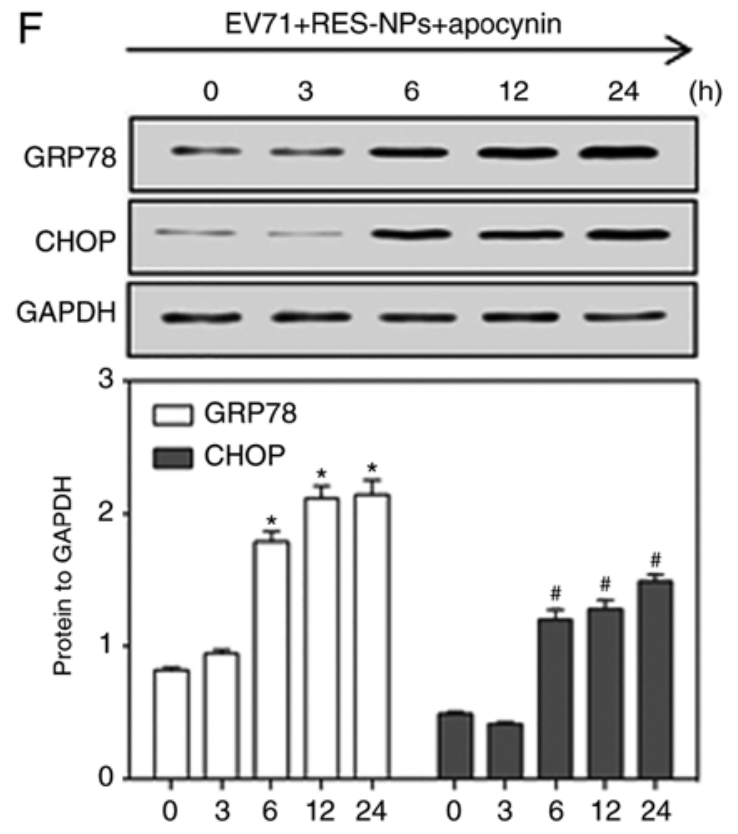

Time of EV71 infection treated with chemicals (h)

Figure 6. Continued. The levels of GRP78 and CHOP were measured in RD cells pretreated with (E) RES-NPs (RES concentration, $200 \mu \mathrm{g} / \mathrm{ml}$ ) alone or (F) RES-NPs (RES concentration, $200 \mu \mathrm{g} / \mathrm{ml})+$ apocynin $(300 \mu \mathrm{M})$ for $0,3,6,12$ and $24 \mathrm{~h}$ using a western blotting assay following protein extraction. Data from three repeat experiments are presented as the mean \pm standard deviation. ${ }^{~} \mathrm{P}<0.05$ vs. $0 \mathrm{~h} \mathrm{p}$-PERK/PERK group; ${ }^{\#} \mathrm{P}<0.05$ vs. $0 \mathrm{~h}$ p-eIF2 $\alpha /$ eIF $2 \alpha$ group; ${ }^{\$} \mathrm{P}<0.05$ vs. 0 h ATF4 group. RES, resveratrol; RES-NPs, resveratrol-loaded nanoparticles; PERK, PKR-like endoplasmic reticulum-resident kinase; $p$-PERK, phosphorylated PERK; eIF2 $\alpha$, eukaryotic initiation factor $2 \alpha$; p-eIF2 $\alpha$, phosphorylated eIF2 $\alpha$; ATF4, activating transcription factor 4; GRP78, glucose regulated protein 78, CHOP, transcription factor CCAAT/enhancer binding protein-homologous protein; EV71, enterovirus 71; RD, rhabdosarcoma.

autophagy is low. However, in the case of pathogen infection, autophagy may be rapidly upregulated (31). In the present study, EV71 infection increased the ratio of LC3-II/cytosolic LC3 (LC3-I) in RD cells at 6, 12 and $24 \mathrm{~h}$ (Fig. 7A), but they revealed a significant reduction in the presence of RES-NPs (RES concentration $=200 \mu \mathrm{g} / \mathrm{ml})($ Fig. 7B). Furthermore, RES-NPs failed to inhibit the ratio of LC3-II/LC3-I when pretreated with the 4-PBA (eIF2 $\alpha$-mediated ERS pathway inhibitor) (Fig. 7C). Concomitantly, red fluorescent-labeled LC3-II antibody was used to detect the level of autophagy and DAPI was used to localize the cells. Fig. 7D demonstrated that the RD cells infected with EV71 alone exhibited brighter red fluorescence compared with the control group, signifying that the EV71 infection may lead to an increase in intracellular LC3-II expression. Conversely, the red fluorescence signals corresponding to the cells treated with the combination of EV71 and RES-NPs were markedly decreased when compared with those cells treated with EV71 only, demonstrating that the use of RES-NPs may significantly prevent intracellular LC3-II expression. These red fluorescence intensity data were quantified, and suggested that RES-NPs may almost completely inhibit the EV71-induced increase in LC3-II expression (Fig. 7E). These data indicated that the RES-NPs inhibited the EV71-induced activation of the ERS-mediated autophagy signaling pathway.

Effect of RES-NPs on EV71-induced inflammatory cytokines secretion and VPI synthesis in RD cells. Previous data have indicated that the occurrence and development of HFMD are associated with excessive inflammation and the immune response in the body (32). Cytokines are a type of low-molecular-weight protein with a broad range of biological activities, induced by immunogens and other stimuli (32). They are able to regulate cell growth and differentiation by regulating their corresponding receptors, and regulate immune responses (32). It has been identified that inflammatory cytokines including IL-6, IL-8 and TNF- $\alpha$ were over-secreted in serum and body fluid of children with HFMD (33). In the present study, compared with the control group, EV71-infected cells exhibited increased secretion levels of IL-6, IL- 8 and TNF- $\alpha$ at 6,12 and $24 \mathrm{~h}$ (Fig. 8A-C). The treatment of RES-NPs (RES concentration $=200 \mu \mathrm{g} / \mathrm{ml}$ ) suppressed the secretion of IL-6, IL-8 and TNF- $\alpha$ in EV71-infected RD cells, and no difference between the control and RES-NPs groups was observed (Fig. 8A-C). These data suggested that RES-NPs may effectively inhibit the secretion of inflammatory cytokines and mitigate the damage of RD cells. Concomitantly, RES-NPs failed to inhibit the secretion of inflammatory cytokines when pretreated with apocynin, the oxidative stress inhibitor, 4-PBA, the ERS inhibitor, or 3-MA, the autophagy inhibitor. Fig. 8D indicated that RES-NPs may effectively inhibit the synthesis of VP1 and mitigate the virus replication in EV71-infected RD cells. In addition, RES-NPs failed to inhibit the synthesis of VP1 when pretreated with the apocynin, 4-PBA or 3-MA (Fig. 8D). These results suggested that oxidative stress/ERS/autophagy signal transduction may be involved in the anti-inflammatory effect and antiviral effect of RES-NPs on EV71-infected RD cells.

\section{Discussion}

EV71 infection may lead to HFMD, aseptic meningitis, encephalitis and poliomyelitis-like paralysis and other diseases (34). 
A

A
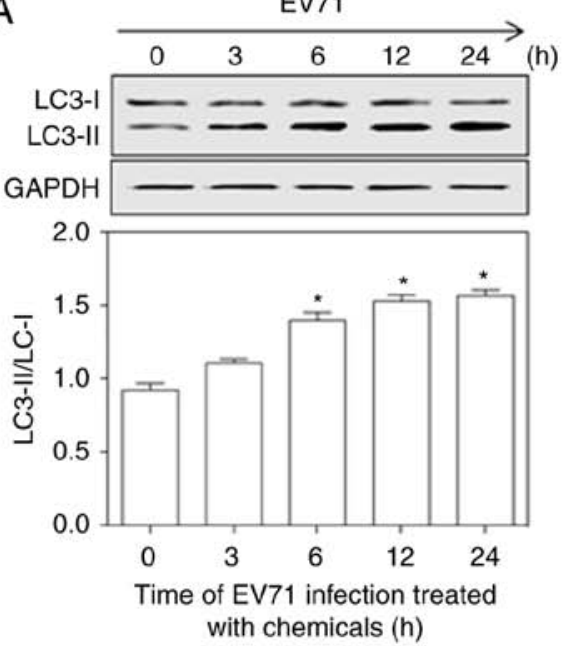

$\mathrm{B}$
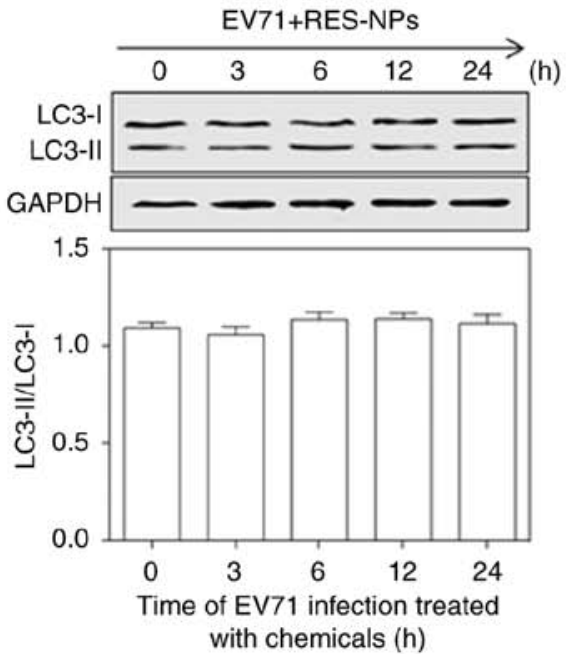

C
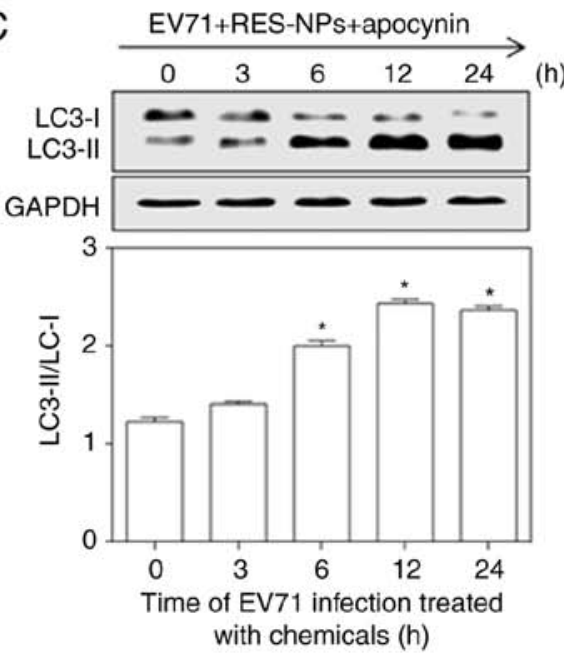

$\mathrm{D}$
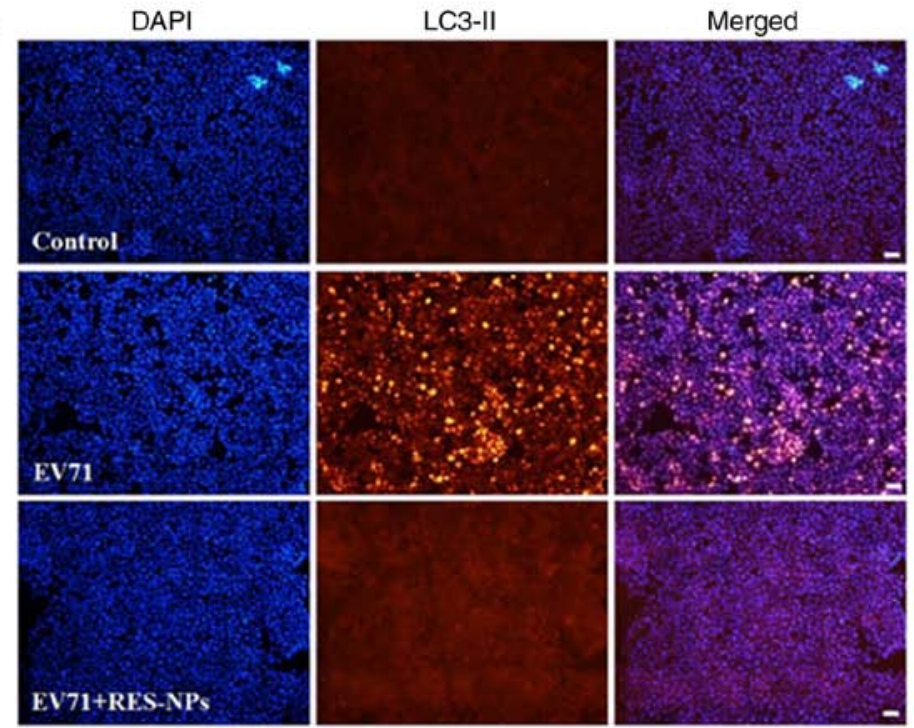

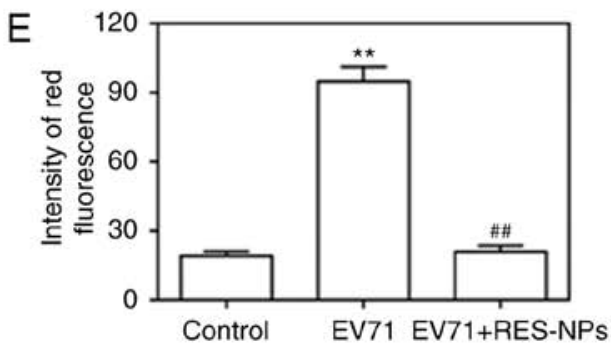

Figure 7. RES-NPs alters the expression levels of autophagy-associated protein LC3-I in EV71-infected RD cells. The RD cells were pretreated with (A) culture medium, (B) RES-NPs (RES concentration, $200 \mu \mathrm{g} / \mathrm{ml}$ ) alone or (C) RES-NPs (RES concentration, 200 $\mu \mathrm{g} / \mathrm{ml})+4-\mathrm{PBA}(5 \mathrm{mM})$ for $0,3,6,12 \mathrm{and} 24 \mathrm{~h}$. The expression levels of LC3-I and LC3-II was measured using a western blotting assay following protein extraction. LC3-I and LC3-II levels were normalized to GAPDH, and the LC3-II/LC3-I ratio was quantitatively analyzed. Data from three repeat experiments are represented as the mean \pm standard deviation. ${ }^{*} \mathrm{P}<0.05$ vs. 0 h group. (D) Fluorescence images of RD cells treated with EV71 alone and the combination of EV71 and RES-NPs (RES concentration, $200 \mu \mathrm{g} / \mathrm{ml}$ ) for $24 \mathrm{~h}$. Scale bar, $50 \mu \mathrm{m}$. (E) Fluorescence intensity of LC3-II expression was quantified. Data from three repeat experiments are presented as the mean \pm standard deviation. ${ }^{* *} \mathrm{P}<0.01$ vs. control; ${ }^{\# \#} \mathrm{P}<0.01$ vs. EV71. RES, resveratrol; RES-NPs, resveratrol-loaded nanoparticles; EV71, enterovirus 71; RD, rhabdosarcoma; PBA, 4-Phenylbutyric acid; LC3, microtubule-associated proteins 1A/1B-light chain 3.

At present, the effectiveness of antiviral drugs, vaccines and interferon treatments in their abilities to completely eradicate the virus is limited $(10,11)$. It has been observed in clinical practice that certain traditional Chinese medicines may be effective in the prevention and treatment of EV71 (35). RES exhibits multiple pharmacological properties, including anti-inflammatory, antibacterial, anti-tumor and antifungal effects, lipid metabolism regulation and cardiovascular protection (14). In addition, RES usually interferes with the signal transduction pathway in the cell to exert its extensive anti-viral effects $(36,37)$. As RES is a polyphenolic compound, it is very polar, with low solubility in water and high solubility in strong polar solvents including chloroform, methanol, ethanol and acetone, resulting in low bioavailability. It is unstable to 

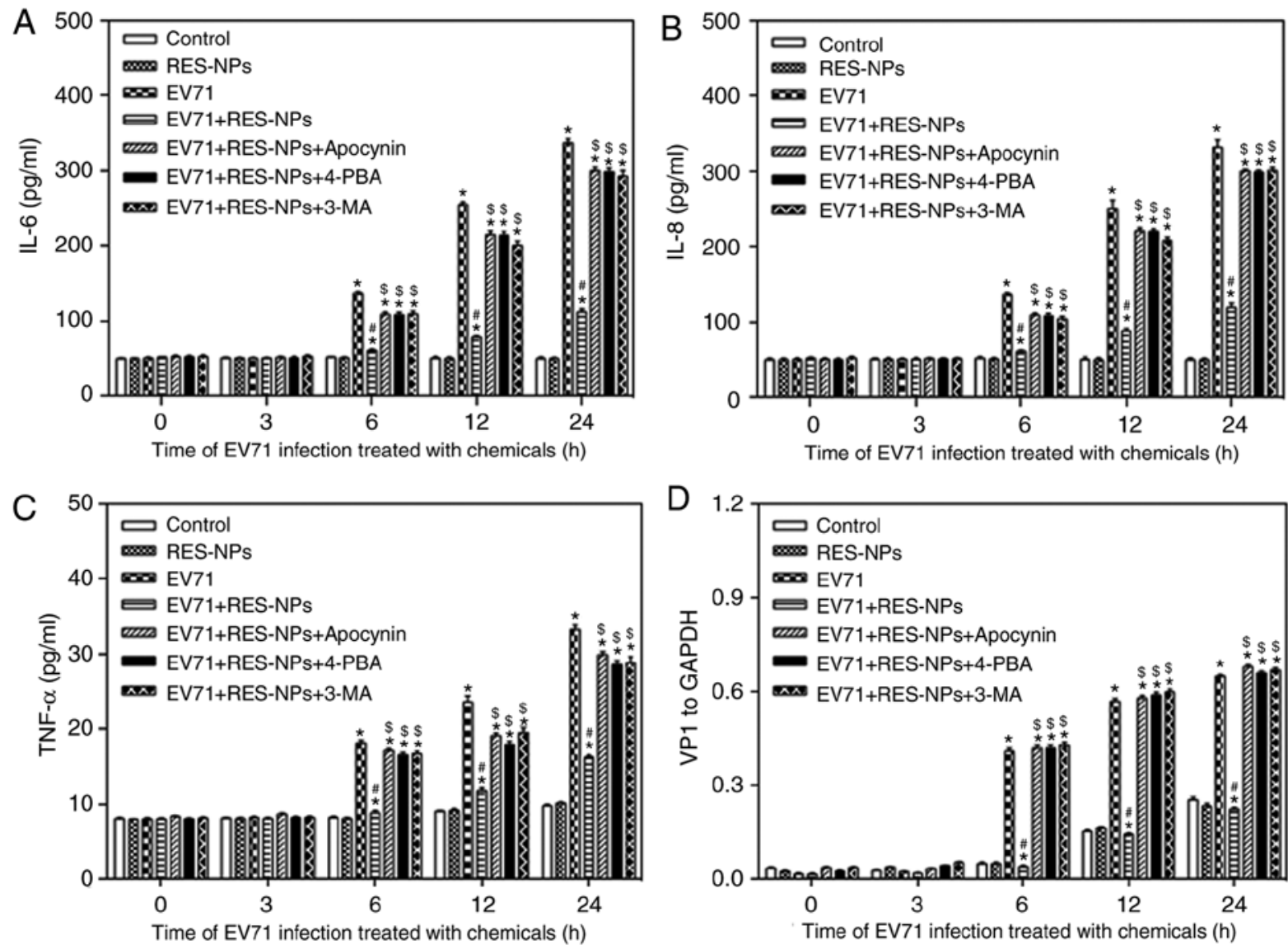

Figure 8. Inhibition of RES-NPs on the several chemokine releases and expression of VP1 protein in EV71-infected RD cells at $24 \mathrm{~h}$. Promotion of (A) IL-6, (B) IL-8 and (C) TNF- $\alpha$ release in RD cells with EV71 infection. The culture supernatants were harvested at 0,3, 6, 12 and $24 \mathrm{~h}$ after infection to measure the release of cytokines using the FLEXMAP 3D platform. (D) VP1 levels were measured using a western blotting assay following protein extraction. VP1 levels were normalized to GAPDH. Quantitative analysis of the expression of VP1. Data from three repeat experiments are presented as the mean \pm standard deviation. ${ }^{*} \mathrm{P}<0.05$ vs. control; ${ }^{\#} \mathrm{P}<0.05$ vs. EV71; ${ }^{\$} \mathrm{P}<0.05$ vs. EV71 + RES-NPs. IL-6, interleukin-6; IL-8, interleukin-8; TNF- $\alpha$, tumor necrosis factor- $\alpha$; RD, rhabdosarcoma; EV71, enterovirus 71; RES, resveratrol; RES-NPs, resveratrol-loaded nanoparticles; Control group, uninfected RD cells; RES-NPs group, uninfected RD cells treated with RES-NPs; EV71 group, EV71 infected RD cells; RES-NPs + EV71 group, RD cells pretreated with RES-NPs (RES concentration, $200 \mu \mathrm{g} / \mathrm{ml}$ ) for $1.5 \mathrm{~h}$ prior to EV71 infection; VP1, major capsid protein VP1.

light and therefore inconvenient for clinical use. NPs use block copolymers to entrap hydrophobic drugs in hydrophobic cores. NP systems may increase the solubility and biocompatibility of hydrophobic drugs. In the present study, an efficient antiviral effect was obtained by using NPs formulations of RES in EV71 infected-RD cells. However, the antiviral effects and mechanism of RES-NPs on EV71 have not been widely studied. The present study confirmed that there was no cytotoxicity of RES-NPs on RD cells at the dose of $200 \mu \mathrm{g} / \mathrm{ml}$. Concomitantly, RES-NPs were able to significantly inhibit CPE caused by EV71, and the inhibitory activity of RES-NPs on EV71 replication was observed to be dose-dependent. When RES-NPs (RES concentration $=200 \mu \mathrm{g} / \mathrm{ml}$ ) were added simultaneously with or after EV71 absorption for $1.5 \mathrm{~h}$, the viral titers in cell supernatant decreased, suggesting that RES-NPs may inhibit EV71 replication in RD cells. These data suggested that the inhibitory activity of RES-NPs on EV71 replication was time-dependent, but independent of viral attachment and penetration.

VP1 is an enterovirus-encoded capsid protein that is exposed on the surface of viral particles and is the major antigenic determinant of EV71 (38). It is also a specific indicator of EV71 replication (38). The data from the present study indicated that the synthesis of VP1 in RD cells was significantly increased at 6-24 $\mathrm{h}$ after EV71 infection, whereas RES-NPs were able to effectively prevent the synthesis of VP1 in RD cells infected with EV71. These results suggested that RES-NPs may exert strong antiviral effects in EV71-infected RD cells, and the mechanism requires additional exploration.

Rhinovirus and respiratory syncytial virus induce oxidative stress in cells $(39,40)$. It has been previously identified that EV71 infection may lead to increased ROS generation (41). MDA is the preferred indicator to evaluate the ROS content in vivo (42). SOD is an important antioxidant enzyme that maintains the free radical homeostasis in the human body (43). The present study demonstrated that RES-NPs may significantly decrease the production of ROS and MDA in EV71-infected RD cells. Concomitantly, RES-NPs may significantly increase the production of SOD in EV71-infected RD cells.

Cells may affect the homeostasis and function of the ER in stress conditions, including bacterial or viral infections (44). A previous research demonstrated that EV71 infection might cause upregulation and aberrant redistribution of GRP78 to the cytosol, thereby facilitating virus replication (45). Under pathological states including viral infection, ER-localized chaperones, including GRP78, are activated, and then the 
unfolded protein response system is initiated, including the PERK/eIF2 $\alpha /$ ATF4 pathway (44). CHOP, also known as growth arrest and DNA damage-inducing gene 153, is a pro-apoptotic transcription factor (46) belonging to the C/EBP transcription factor family that heterodimerizes with other C/EBPs and may be upregulated by the PERK/eIF2 $\alpha /$ ATF4 pathway (47). In the present study, the western blot analysis data revealed that exposure to EV71 in RD cells increased the expression of p-PERK, p-eIF2 $\alpha$, ATF4, GRP78 and CHOP, indicating that the PERK/eIF2 $\alpha /$ ATF4 pathway participated in EV71-induced virus replication. Following pretreatment with RES-NPs, the increased expression of p-PERK, p-eIF2 $\alpha$, ATF4, GRP78 and CHOP was significantly inhibited in the EV71-infected RD cells. Notably, RES-NPs failed to inhibit the expression of p-PERK, p-eIF2 $\alpha$, ATF4, GRP78 and CHOP when pretreated with apocynin. These results indicated that RES-NPs may effectively protect the RD cells against EV71 infection, through inhibiting the activation of the oxidative stress-mediated ERS pathway and extenuated damage of the RD cells.

The importance of autophagy in viral infections has become increasingly apparent and has become an important topic of study (48). Cell autophagy is closely associated with the innate immune system of the body. It may serve roles in the identification and presentation of viral antigens, activation of natural immune responses and clearance of the virus. Conversely, the virus may also use the regulation of autophagy to escape the anti-virus response of the body, and to maintain their own survival and reproduction (49). There have been a number of studies on the induction of cell autophagy by viral infection. For example, membrane cofactor protein is used as a receptor for cell surface-mediated invasion of various pathogens (50). The successive waves of autophagy result from distinct molecular pathways and appear to be associated with anti- and/or pro-measles virus consequences (51). Previous studies have also identified that viral infection may induce autophagy through the activation of the ERS signaling pathway $(52,53)$. When autophagy occurs, LC3-I in the cytoplasm is recruited to the autophagosome to form LC3-II (49). Therefore, the LC3-II/LC3-I ratio may be used as an indicator to reflect the level of autophagy in cells (49). In the present study, the western blot analysis and immunofluorescence data revealed that exposure to EV71 in RD cells increased the LC3-II/LC3-I ratio and LC3-II expression, indicating that the autophagy pathway participated in EV71 induced virus replication. Following pretreatment with RES-NPs, the increased LC3-II/LC3-I ratio and LC3-II expression was significantly inhibited in EV71-infected RD cells. Notably, RES-NPs failed to inhibit the LC3-II/LC3-I ratio when pretreated with 4-PBA, the ERS inhibitor. These data indicated that RES-NPs may effectively protect the host cells against EV71 infection through inhibition of the activation of ERS-mediated autophagy pathway and extenuated damage to the RD cells.

Cytokines serve an important role in the inflammatory response in HFMD, are involved in the immune and inflammatory reactions and affect the intensity and duration of the reaction (33). The investigation of cytokines has identified that there are $>200$ types of human cytokines, including IL-6, IL- 8 and TNF- $\alpha(54,55)$. The results from the present study suggested that the secretion of IL- 6 , IL- 8 and TNF- $\alpha$ significantly increased in EV71 infected RD cells. Concomitantly, the western blot analysis results suggested that the expression of VP1 was significantly increased in EV71-infected RD cells. Following pretreatment with RES-NPs, VP1 expression levels and the secretion of IL-6, IL-8 and TNF- $\alpha$ were observed to be decreased in EV71-infected RD cells. These data indicated that RES-NPs may effectively inhibit the inflammatory reaction and virus replication in EV71-infected RD cells. Notably, 3 inhibitors targeting oxidative stress, ERS or autophagy inhibited the anti-inflammatory and antiviral effects of RES-NPs on EV71-infected RD cells, suggesting that the RES-NPs-induced anti-inflammatory and antiviral effects were closely associated with the oxidative stress/ERS/autophagy pathway.

In conclusion, the present study demonstrated that RES-NPs inhibited viral replication and the inflammatory reaction of EV71-infected RD cells by inhibiting the synthesis of VP1 protein and the secretion of cytokines, and that RES-NPs served their role through inhibiting the oxidative stress-mediated ERS/autophagy pathway. These results indicate that RES-NPs may be a feasible alternative strategy for the treatment of EV71 infection. The underlying mechanism requires additional in vitro and in vivo studies, in order to examine the oxidative stress-mediated ERS/autophagy pathway.

\section{Acknowledgements}

The authors would like to thank Mr. Ming Liu of Changchun Institute of Applied Chemistry, Chinese Academy of Sciences for offering technical guidance for the synthesis of nanoparticles.

\section{Funding}

The present study was supported by a grant from the Jilin Provincial Science and Technology Department in China (grant no. 20130206040SF).

\section{Availability of data and materials}

All data generated or analyzed during this study are included in this published article.

\section{Authors' contributions}

ND and FW conceived and designed the study. XL, WB, BW, GX and FW performed the experiments. ND, XL, WB, BW and GX wrote the paper. FW reviewed and edited the manuscript. All authors read and approved the final manuscript.

\section{Ethics approval and consent to participate}

Not applicable.

\section{Patient consent for publication}

Not applicable.

\section{Competing interests}

The authors declare that they have no competing interests. 


\section{References}

1. Lin JY and Shih SR: Cell and tissue tropism of enterovirus 71 and other enteroviruses infections. J Biomed Sci 21: 18, 2014.

2. Zhou ZM, Xu Y, Hu CS, Pan QJ and Wei JJ: Epidemiological features of hand, foot and mouth disease during the period of 2008-14 in Wenzhou, China. J Trop Pediatr 63: 182-188, 2017.

3. Garmaroudi FS, Marchant D, Hendry R, Luo H, Yang D, Ye X, Shi J and McManus BM: Coxsackievirus B3 replication and pathogenesis. Future Microbiol 10: 629-653, 2015.

4. Huang YT, Liao JT, Yen LC, Chang YK, Lin YL and Liao CL: Japanese encephalitis virus replicon-based vaccine expressing enterovirus-71 epitope confers dual protection from lethal challenges. J Biomed Sci 22: 74, 2015.

5. Gaaloul I, Riabi S, Harrath R, Hunter T, Hamda KB, Ghzala AB, Huber S and Aouni M: Coxsackievirus B detection in cases of myocarditis, myopericarditis, pericarditis and dilated cardiomyopathy in hospitalized patients. Mol Med Rep 10: 2811-2818, 2014

6. Lee KY: Enterovirus 71 infection and neurological complications. Korean J Pediatr 59: 395-401, 2016.

7. Wang Y, Zou G, Xia A, Wang X, Cai J, Gao Q, Yuan S, He G, Zhang S, Zeng $M$ and Altmeyer R: Enterovirus 71 infection in children with hand, foot, and mouth disease in Shanghai, China: Epidemiology, clinical feature and diagnosis. Virol J 12: 83, 2015

8. Esposito $\mathrm{S}$ and Principi N: Hand, foot and mouth disease: Current knowledge on clinical manifestations, epidemiology, aetiology and prevention. Eur J Clin Microbiol Infect Dis 37: 391-398, 2018

9. Yang ZY, Chen XQ, Sun D and Wei D: Mortality in children with severe hand, foot and mouth disease in Guangxi, China. Indian Pediatr 55: 137-139, 2018

10. Huang X, Zhang X, Wang F, Wei H, Ma H, Sui M, Lu J, Wang H, Dumler JS, Sheng G and Xu B: Clinical efficacy of therapy with recombinant human interferon $\alpha 1 b$ in hand, foot, and mouth disease with enterovirus 71 infection. PLoS One 11: e0148907, 2016.

11. Zhu Z, Ye X, Ku Z, Liu Q, Shen C, Luo H, Luan H, Zhang C, Tian S, Lim C, et al: Transcutaneous immunization via rapidly dissolvable microneedles protects against hand-foot-and-mouth disease caused by enterovirus 71. J Control Release 243: 291-302, 2016.

12. Jiewei T, Lei W, Xiufeng L, Heming Z, Xiaoguang L, Haiyan F and Yongqiang T: Microbial transformation of resveratrol by endophyte Streptomyces sp. A12 isolated from Polygonum cuspidatum. Nat Prod Res 32: 2343-2346, 2018.

13. Zhao G, Jiang K, Wu H, Qiu C, Deng G and Peng X: Polydatin reduces staphylococcus aureus lipoteichoic acid-induced injury by attenuating reactive oxygen species generation and TLR2-NFאB signaling. J Cell Mol Med 21: 2796-2808, 2017.

14. Heo JR, Kim SM, Hwang KA, Kang JH and Choi KC: Resveratrol induced reactive oxygen species and endoplasmic reticulum stress-mediated apoptosis, and cell cycle arrest in the A375SM malignant melanoma cell line. Int J Mol Med 42: 1427-1435, 2018.

15. Huang YT, Chen YY, Lai YH, Cheng CC, Lin TC, Su YS, Liu CH and Lai PC: Resveratrol alleviates the cytotoxicity induced by the radiocontrast agent, ioxitalamate, by reducing the production of reactive oxygen species in HK-2 human renal proximal tubule epithelial cells in vitro. Int J Mol Med 37: 83-91, 2016.

16. Li K, Li Y, Mi J, Mao L, Han X and Zhao J: Resveratrol protects against sodium nitroprusside induced nucleus pulposus cell apoptosis by scavenging ROS. Int J Mol Med 41: 2485-2492, 2018 .

17. Zhang L, Li Y, Gu Z, Wang Y, Shi M, Ji Y, Sun J, Xu X, Zhang L, Jiang $J$ and Shi W: Resveratrol inhibits enterovirus 71 replication and pro-inflammatory cytokine secretion in rhabdosarcoma cells through blocking IKKs/NF- $\mathrm{KB}$ signaling pathway. PLoS One 10: e0116879, 2015 .

18. Zhao X, Xu J, Song X, Jia R, Yin Z, Cheng A, Jia R, Zou Y, Li L, Yin L, et al: Antiviral effect of resveratrol in ducklings infected with virulent duck enteritis virus. Antiviral Res 130 93-100, 2016

19. Li K, Liu Y, Zhang S, Xu Y, Jiang J, Yin F, Hu Y, Han B, Ge S, Zhang L and Wang Y: Folate receptor-targeted ultrasonic PFOB nanoparticles: Synthesis, characterization and application in tumor-targeted imaging. Int J Mol Med 39: 1505-1515, 2017.

20. Jiang X, Zhong Y, Zheng L and Zhao J: Nano-hydroxyapatite/ collagen film as a favorable substrate to maintain the phenotype and promote the growth of chondrocytes cultured in vitro. Int $\mathrm{J}$ Mol Med 41: 2150-2158, 2018
21. Wu L, Chen M, Mao H, Wang N, Zhang B, Zhao X, Qian J and Xing C: Albumin-based nanoparticles as methylprednisolone carriers for targeted delivery towards the neonatal $\mathrm{Fc}$ receptor in glomerular podocytes. Int J Mol Med 39: 851-860, 2017.

22. Xu C, Peng Y, Zhang Q, Xu XP, Kong XM and Shi WF: USP4 positively regulates RLR-induced NF- $\mathrm{KB}$ activation by targeting TRAF6 for K48-linked deubiquitination and inhibits enterovirus 71 replication. Sci Rep 8: 13418, 2018.

23. Hamilton MA, Russo RC and Thurston RV: Trimmed Spearman-Karber method for estimating median lethal concentrations in toxicity bioassays. Environ Sci Technol 11: 714-719, 1977.

24. Reed LJ and Muench H: A simple method of estimating fifty percent endpoints. Am J Epidemiol 27: 493-497, 1938.

25. Li J, Zhou Y, Zhang W, Bao C and Xie Z: Relief of oxidative stress and cardiomyocyte apoptosis by using curcumin nanoparticles. Collolds Surf B Biointerfaces 153: 174-182, 2017.

26. Song S, Tan J, Miao Y and Zhang Q: Crosstalk of ER stress-mediated autophagy and ER-phagy: Involvement of UPR and the core autophagy machinery. J Cell Physiol 233: 3867-3874, 2018.

27. Fraser JE, Wang C, Chan KW, Vasudevan SG and Jans DA: Novel dengue virus inhibitor 4-HPR activates ATF4 independent of protein kinase R-like endoplasmic reticulum kinase and elevates levels of eIF $2 \alpha$ phosphorylation in virus infected cells. Antiviral Res 130: 1-6, 2016.

28. Thomas M, Davis T, Loos B, Sishi B, Huisamen B, Strijdom H and Engelbrecht AM: Autophagy is essential for the maintenance of amino acids and ATP levels during acute amino acid starvation in MDAMB231 cells. Cell Biochem Funct 36: 65-79, 2018.

29. Lekli I, Haines DD, Balla G and Tosaki A: Autophagy: An adaptive physiological countermeasure to cellular senescence and ischaemia/reperfusion-associated cardiac arrhythmias. J Cell Mol Med 21: 1058-1072, 2017.

30. Schroeder S, Zimmermann A, Carmona-Gutierrez D, Eisenberg T, Ruckenstuhl C, Andryushkova A, Pendl T, Harger A and Madeo F: Metabolites in aging and autophagy. Microb Cell 1: 110-114, 2014.

31. Deretic V and Klionsky DJ: Autophagy and inflammation: A special review issue. Autophagy 14: 179-180, 2018.

32. Shao P, Wu X, Li H, Wu Z, Yang Z and Yao H: Clinical significance of inflammatory cytokine and chemokine expression in hand, foot and mouth disease. Mol Med Rep 15: 2859-2866, 2017.

33. Shang W, Qian S, Fang L, Han Y and Zheng C: Association study of inflammatory cytokine and chemokine expression in hand foot and mouth disease. Oncotarget 8: 79425-79432, 2017.

34. Yi EJ, Shin YJ, Kim JH, Kim TG and Chang SY: Enterovirus 71 infection and vaccines. Clin Exp Vaccine Res 6: 4-14, 2017

35. Wang M, Tao $\mathrm{L}$ and $\mathrm{Xu} \mathrm{H}$ : Chinese herbal medicines as a source of molecules with anti-enterovirus 71 activity. Chin Med 11: 2 , 2016.

36. Shi Y, Li Y, Huang C, Ying L, Xue J, Wu H, Chen Z and Yang Z: Resveratrol enhances HBV replication through activating Sirt1-PGC-1 $\alpha$-PPAR $\alpha$ pathway. Sci Rep 6: 24744, 2016.

37. Liu T, Zang N, Zhou N, Li W, Xie X, Deng Y, Ren L, Long X, Li S, Zhou L, et al: Resveratrol inhibits the TRIF-dependent pathway by upregulating sterile alpha and armadillo motif protein, contributing to anti-inflammatory effects after respiratory syncytial virus infection. J Virol 88: 4229-4236, 2014.

38. Li X, Huang Y, Sun M, Ji H, Dou H, Hu J, Yan Y, Wang X and Chen L: Honeysuckle-encoded microRNA2911 inhibits enterovirus 71 replication via targeting VP1 gene. Antiviral Res 152: 117-123, 2018.

39. Mihaylova VT, Kong Y, Fedorova O, Sharma L, Dela Cruz CS, Pyle AM, Iwasaki A and Foxman EF: Regional differences in airway epithelial cells reveal tradeoff between defense against oxidative stress and defense against rhinovirus. Cell Rep 24: 3000-3007.e3, 2018

40. Griffiths C, Drews SJ and Marchant DJ: Respiratory syncytial virus: Infection, detection, and new options for prevention and treatment. Clin Microbiol Rev 30: 277-319, 2017.

41. Cheng ML, Weng SF, Kuo CH and Ho HY: Enterovirus 71 induces mitochondrial reactive oxygen species generation that is required for efficient replication. PLoS One 9: e113234, 2014.

42. Guo S, Yao Q, Ke Z, Chen H, Wu J and Liu C: Resveratrol attenuates high glucose-induced oxidative stress and cardiomyocyte apoptosis through AMPK. Mol Cell Endocrinol 412: 85-94, 2015. 
43. Yang J, Yin HS, Cao YJ, Jiang ZA, Li YJ, Song MC, Wang YF, Wang ZH, Yang R, Jiang YF, et al: Arctigenin attenuates ischemia/reperfusion induced ventricular arrhythmias by decreasing oxidative stress in rats. Cell Physiol Biochem 49: 728-742, 2018

44. Hu DD, Mai JN, He LY, Li PQ, Chen WX, Yan JJ, Zhu WD, Deng L, Wei D, Liu DH, et al: Glucocorticoids prevent enterovirus 71 capsid protein VP1 induced calreticulin surface exposure by alleviating neuronal ER stress. Neurotox Res 31 : 204-217, 2017.

45. Jheng JR, Wang SC, Jheng CR and Horng JT: Enterovirus 71 induces dsRNA/PKR-dependent cytoplasmic redistribution of GRP78/BiP to promote viral replication. Emerg Microbes Infect 5: e23, 2016.

46. Hosomi S, Grootjans J, Huang YH, Kaser A and Blumberg RS New insights into the regulation of natural-killer group 2 member D (NKG2D) and NKG2D-ligands: Endoplasmic reticulum stress and CEA-related cell adhesion molecule 1. Front Immunol 18: 1324, 2018.

47. Zhong F, Xie J, Zhang D, Han Y and Wang C: Polypeptide from chlamys farreri suppresses ultraviolet-B irradiation-induced apoptosis through restoring ER redox homeostasis, scavenging ROS generation, and suppressing the PERK-eIF2a-CHOP pathway in HaCaT cells. J Photochem Photobiol B 151: 10-16, 2015.

48. Jung KI, Pyo CW and Choi SY: Influenza A virus-induced autophagy contributes to enhancement of virus infectivity by SOD1 downregulation in alveolar epithelial cells. Biochem Biophys Res Commun 498: 960-966, 2018.
49. Wei Y, Cao XN, Tang XL, Shen LJ, Lin T, He DW, Wu SD and Wei GH: Urban fine particulate matter (PM2.5) exposure destroys blood-testis barrier (BTB) integrity through excessive ROS-mediated autophagy. Toxicol Mech Methods 28: 302-319, 2018.

50. Richetta C, Grégoire IP, Verlhac P, Azocar O, Baguet J, Flacher M, Tangy F, Rabourdin-Combe $\mathrm{C}$ and Faure M: Sustained autophagy contributes to measles virus infectivity. PLoS Pathog 9: e1003599, 2013.

51. Rozières A, Viret $C$ and Faure $M$ : Autophagy in measles virus infection. Viruses 9: pii: E359, 2017.

52. Yan Y, Liu S, Li M, Zhao Y, Shao X, Hang M and Bu X: Recombinant Newcastle disease virus expressing human IFN- $\lambda 1$ (rL-hIFN- $\lambda 1$ )-induced apoptosis of A549 cells is connected to endoplasmic reticulum stress pathways. Thorac Cancer 9: 1437-1452, 2018.

53. Dash S, Chava S, Aydin Y, Chandra PK, Ferraris P, Chen W, Balart LA, Wu T and Garry RF: Hepatitis $\mathrm{C}$ virus infection induces autophagy as a prosurvival mechanism to alleviate hepatic ER-stress response. Viruses 8: pii: E150, 2016.

54. Lee JY, Son M, Kang JH and Choi UY: Serum interleukin-6 levels as an indicator of aseptic meningitis among children with enterovirus 71-induced hand, foot and mouth disease. Postgrad Med 130: 258-263, 2018.

55. Zhu L, Li W, Qi G, Liu N, Sheng L, Shang L and Qi B: The immune mechanism of intestinal tract Toll-like receptor in mediating EV71 virus type severe hand-foot-and-mouth disease and the MAPK pathway. Exp Ther Med 13: 2263-2266, 2017. 